\title{
Diabetes Health, Residence \& Metabolism in Asians: the DHRMA study, research into foods from the Indian subcontinent - a blinded, randomised, placebo controlled trial
}

\author{
Jeetesh V Patel ${ }^{1,2}$, Elizabeth A Hughes ${ }^{1 *}$, Gregory YH Lip ${ }^{2}$ and Paramjit S Gill ${ }^{3}$
}

\begin{abstract}
Background: Coronary heart disease (CHD) is highly prevalent amongst the South Asian communities in Britain. The reasons for this excess CHD risk are multifactorial, but in part relate to a susceptibility to diabetes mellitus where the aberrant metabolism of non-esterified fatty acids (NEFA) and glucose are likely to underpin vascular disease in this population. Dietary intervention is an important and first line approach to manage increased CHD risk. However, there is limited information on the impact of the South Asian diet on CHD risk.

Methods/Design: The Diabetes Health, Residence \& Metabolism in Asians (DHRMA) study is a blinded, randomised, placebo controlled trial that analyses the efficacy of reduced glycaemic index (Gl) staples of the South Asian diet, in relation to cardio-metabolic risk factors that are commonly perturbed amongst South Asian populations - primarily glucose, fatty acid and lipoprotein metabolism and central adiposity. Using a 10-week dietary intervention study, 50 healthy South Asians will be randomised to receive either a DHRMA (reduced Gl) supply of chapatti (bread), stone ground, high protein wheat flour and white basmati rice (high bran, unpolished) or commercially available (leading brand) versions chapatti wheat flour and basmati rice. Volunteers will be asked to complete a $75 \mathrm{~g}$ oral glucose tolerance test at baseline and at 10-weeks follow-up, where blood metabolites and hormones, blood pressure and anthropometry will also be assessed in a standardised manner.
\end{abstract}

Discussion: It is anticipated that the information collected from this study help develop healthy diet options specific (but not exclusive) for South Asian ethnic communities.

Trial registration

Current Controlled Trials ISRCTN02839188

\section{Background}

Coronary heart disease (CHD) is the leading cause of mortality and morbidity amongst South Asians living in the UK (people originating from the Indian subcontinent), who have a $50 \%$ greater risk of dying prematurely from this affliction than the general population $[1,2]$. This increased CHD risk is multifactorial, but in part is likely to be influenced by diabetes mellitus [3], which is more common amongst South Asian groups [4]. Indeed,

\footnotetext{
* Correspondence: elizabeth.hughes3@nhs.net

${ }^{1}$ Metabolic Medicine, Sandwell General Hospital, Sandwell and West Birmingham Hospitals NHS Trust, Lyndon, West Bromwich, Lyndon (B71 4HJ), UK

Full list of author information is available at the end of the article
}

CHD risk in South Asians is coordinated with the frequent clustering of metabolic risk factors that includes aberrant glucose and lipid metabolism[5,6], which may represent the commonality between diabetogenesis and atherogenesis in this population. These metabolic risk factors are recognised to be associated with more advanced atherosclerotic vascular disease [7] and increased cardiovascular mortality $[8,9]$.

There is an urgent need for effective 'targeted' approaches in the prevention and management of CHD and the associated metabolic risk in South Asians. Dietary intervention remains a 'first line' approach to manage this increased risk. While dietary health promotion approaches to the management and prevention of $\mathrm{CHD}$ 
is availible for South Asians (i.e diet leaflets and health DVDs, websites such as South Asian health [10]), much of the scientific evidence that such material is based upon uses findings in populations other than South Asians. For South Asian diabetics, general health promotion material has had limited impact [11]. South Asians have also been excluded from major diabetes and cardiovascular clinical trials [12]. Reasons for this are complex, and it is not clear what the range of contributory factors are, what are the main reasons and whether the real issue is one of 'planned exclusion', 'inadvertent exclusion', 'non-participation' or a mixture of these. There is a need to increase South Asian participation in research.

\section{Dietary transition and cardiovascular risk in South Asians} The present study [DHRMA] was specifically developed to advance findings from an epidemiological study of CHD risk in a population of Indian migrants living in the UK. In this study, nutritional intake, lifestyle, glucose tolerance and CHD risk were compared between Indians living in Sandwell (UK) and their contemporaries still living in villages of origin in rural India [13]. While diabetes prevalence was generally high (15\% irrespective of site), in India it was less frequently accompanied by metabolic CHD risk factors such as raised triglycerides and central obesity. The greater metabolicCHD risk amongst the migrant Indians was underpinned by dietary change, a transition towards higher energy and fat intake at the expense of carbohydrate. Data also suggested a background of higher glucose excursions and unregulated NEFA metabolism in Indian populations [14], which has been reported elsewhere as ethnic differences in NEFA profiles following oral glucose challenges [15]. NEFA metabolism may be a key driver for the major CHD risk of these communities, through its role on lipid metabolism and hepatic insulin resistance [16].

\section{Glycaemic index in South Asian foods}

Reducing postprandial glucose and NEFA concentrations may be a desirable option in the dietary management of metabolic-CHD risk in South Asians [17]. In recent years the 'glycaemic index' (GI) (a ranking system for carbohydrates based on their immediate effect on blood glucose levels) has emerged as a classification system for carbohydrate-containing food, where consumption of high GI meals in comparison with energy- and nutrient-controlled low GI foods are adversely associated with glucose intolerance [18]. The GI of foods relates to the nature of monosaccharides, starches, fat, protein and fibre it contains, and the method with which it is cooked. Typically, stone-ground breads have a low GI (high protein and fibre), which is why stone- ground chapatti flour is also likely to have a low GI, compared to other more refined versions (devoid of bran). Basmati rice has a high amylase content, which confers a low GI, and a higher bran content is likely to lower GI further, especially in an unpolished (i.e. high bran) preparation. Importantly, low GI foods are shown to reduce hyperglycaemia, hyperinsulinaemia and postprandial circulating NEFA [19]. While South Asians resident in Britain have varied diets (influenced by culture, religion and British culture), many migrants still subscribe to diets that include staples of carbohydrate such as breads (chapatti, roti, naan) and rice [20]. The industrialisation of food processing and relative affluence has promoted the consumption of more refined foods (high GI) both in India and the UK. In South India [21], postprandial glucose excursions were favourably delayed by staple foods prepared and eaten there, but these foods have yet to be assessed in Britain amongst Indian migrant populations.

\section{Objectives and hypothesis of DHRMA}

The purpose of DHRMA is to provide the scientific basis to help regenerate cultural traditions in food intake, with the aim to develop dietary CHD management options, specifically tailored (but not exclusively) for people of South Asian origin living in the UK. DHRMA is a novel project, as these foods are not commercially available, and the study plan is based on pilot findings from our own research and developed with experience from our ongoing programme of CHD risk screening in ethnic minorities (Healthy Hearts), where 900 individuals have been assessed using a community based approach. [22]

\section{Objectives are as follows}

(i) to establish the GI of existing (ie. produced in the UK) traditional, and regenerated (see (ii)) food staples of South Asian cuisine (specifically chapatti flour and basmati rice).

(ii) to develop will DHRMA test foods that have been specifically that are processed in a similar fashion to those available in rural India: basmati rice that is polished to a low level (less bran removed, grain quality distribution ratio score by KETT (Tokyo, Japan) of $<35 \%)^{*}$, and stone-ground chapatti flour with added grains (oats, barley and chick pea).

(iii)to determine the efficacy of low GI DHRMA foods on indices of diabetes and CHD risk using a blinded, randomised controlled trial.

Note $^{*}$ KETT is an industry standard originating from Japan - a score based on the whiteness of rice. Generally amongst basmati rice sold in the UK, this score is around $40-44 \%$. 
The DHRMA study will focus on testing the hypothesis that a 10-week supply of DHRMA foods (reduced GI supply of chapatti stone ground, high protein wheat flour and high bran, unpolished white basmati rice) to healthy South Asians will result in favourable changes in cardio-metabolic risk factors (glucose tolerance, fatty acid, triglyceride and HDL cholesterol metabolism and central adiposity) as compared those randomised to commercially popular (market leaders) versions of chapatti flour and white basmati rice.

\section{Methods/Design}

Ethical approval for the study was provided by North Staffordshire Research Ethics Committee (REC reference 08/H1204/130), and all prospective volunteers for the DHRMA study will undergo an informed consent process. The DHRMA study is split into two parts, (i) the assessment of glycaemic index in Indian foods and (ii) a dietary intervention trial.

\section{Development of DHRMA low glycaemic index foods}

The Study will be undertaken in the area of Sandwell and West Birmingham, at Sandwell and West Birmingham Hospitals NHS trust (UK). Healthy volunteers (body mass-index between $18-25 \mathrm{~kg} / \mathrm{m}^{2}$, no known cardiovascular disease or associated medication, normal glucose tolerance) will be approached for this study from local communities [22] as well as hospital staff. The GI will be measured using FAO/WHO expert consultation (1998) guidelines. Briefly, an eight point capillary blood glucose profile will be measured over a 2 hour period (i.e. $15 \mathrm{~min}$ intervals) following the administration of a $50 \mathrm{~g}$ glucose load in each prospective volunteer after an overnight fast. Volunteers will then be invited for repeat visits where a $50 \mathrm{~g}$ glucose equivalent from test foods will be administered (done in triplicate for as recommended by the FAO/WHO guidelines).

The preparation of chapattis (ingredients, size and cooking time) and rice (water added and cooking time) will be standardised by researchers and subjects will be advised a standard level of activity during the study period. The test foods will be eaten over 15 minutes with water. Capillary blood samples will be analysed using a standard capillary glucose monitor (quality assurance monitored, Roche Accutrend GC, Roche UK). A capillary blood glucose response for curve for each test food will be plotted, and with each subject, the GI for the food will be the proportion of this area as a percentage of the response to $50 \mathrm{~g}$ of glucose.

\section{Interventional trial}

This is a 10-week, blinded, parallel, randomised intervention trial in South Asians either DHRMA versions of stone ground chapatti flour and high bran white Basmati rice or the commercially popular white chapatti flour (Elephant atta, Premier Foods, UK) and white Basmati (Tilda, UK) will be supplied to participants.

The Inclusion criteria will include age $<55$ yrs, BMI $<30 \mathrm{~kg} / \mathrm{m}^{2}$, systolic/diastolic BP $<140 / 90 \mathrm{mmHg}$ (no antihypertensive use), South Asian ethnicity and use of chapatti flour or rice as part of their normal diet $(>3$ times a week) and $>50 \%$ of energy derived from carbohydrates and $<30 \%$ from fat - determined by 4 -day food diaries, used previously [13]).

A total of 50 subjects will be randomised onto either arm in a blinded fashion, and supplied with study carbohydrates (see Figure 1). The study carbohydrates will be packaged by our industrial collaborator (East End Foods, UK), who randomise and allocate individual packet numbers to each test food (information relating to the contents will be stored with our collaborator and so blinded to study researchers and the study participants). The supply of rice and flour will be in clear, unlabelled $15 \mathrm{~kg}$ bags packaged within a white box with an assigned randomisation number and trial details. Random number allocation will be through a computer generated system, with no provision for factorisation.

Each participant will be asked to attend three visits (screen, randomisation and follow-up). The screening visit will be used to initiate the consent process blood, and to assess inclusion criteria (eg dietary intake).

At randomisation and follow-up, blood pressure and anthropometry will be measured and an OGTT will be performed. Subjects will also be asked to complete a 4day dietary record at randomisation and follow-up. The main metabolic measures will be 10 week changes in OGTT metabolites and hormones (glucose, insulin, NEFA), adiponectin, leptin and lipids and lipoproteins (including serum triglycerides and HDL cholesterol).

\section{Power calculation}

The sample size was calculated on the results from our migration study [13] and dietary intervention study [23] where we found a $0.56(\mathrm{SD}=0.34)$ fall in CHD risk using the biomarker $\mathrm{C}$-reactive protein for individuals on the substitution dietary intervention and no significant reduction in the other groups. Using a paired ttest, at $80 \%$ power, $\alpha<0.05,25$ subjects/arm will allow the detection of a $1 \mathrm{mmol}$ difference in $2 \mathrm{hr}$ glucose and $0.15 \mathrm{mmol}$ change in NEFA suppression (this is $1 / 2$ the difference seen between glucose tolerant and intolerant Indian Gujaratis in our migration study [14]).

\section{Discussion}

The DHRMA study aims to investigate key staples in the South Asian diet and provides the basis for culturally specific dietary options for the management of $\mathrm{CHD}$ risk, in addition to a better understanding of the 


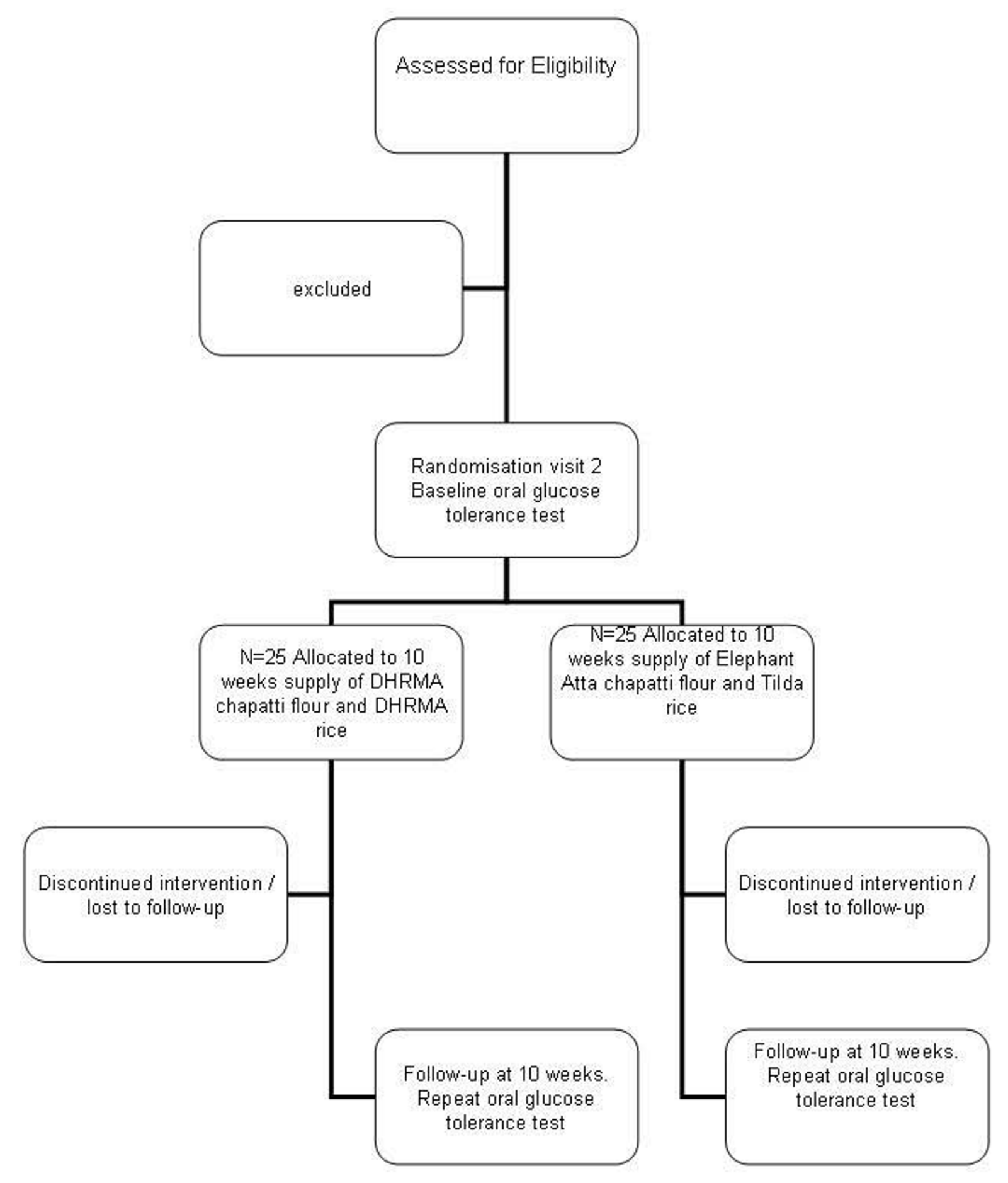

Figure 1 Study Flow-chart.

cardiovascular-metabolic risk in this group. The research focuses on the efficacy of low glycaemic index foods, which have been shown to be beneficial in relation to metabolic processes, and specifically, those that are reported to contribute to cardiovascular risk amongst South Asian populations.

The DHRMA study makes the assumption that it is the quality of carbohydrate that influences cardiovascular 
risk in South Asians. From our previous work we observed that it was a transition from a diet high in carbohydrates to one with reduced energy from carbohydrates that promoted an adverse risk in South Asians [13]. However, we were not able to analyse the quality of the carbohydrate. Some key nutritional deficiencies have been highlighted for this population, which are not under investigation in the current study. For example, South Asians living in Britain also have both lower and altered vitamin D metabolism [24,25], which is consistent with observations amongst migrant South Asians elsewhere [26]. Long chain omega-3 fatty acids (Omega-3 PUFA) are accepted as a treatment for hypertriglyceridaemia and provide protection against CHD $[27,28]$. Low levels of omega-3 fattys acids have been consistently reported as a risk factor of CHD in South Asians living in urban, rural and UK settings [29-32].

By using foods from the Indian subcontinent, the DHRMA study aims to regenerate traditions in diet, likely to be effective in elderly South Asians, and will also provide an additional management angle for clinicians. Hence, the data will provide an evidence base for a 'tailored approach' to cardiovascular risk management in this high risk population.

\section{Funding}

The DHRMA study was funded by the British Heart Foundation (Project Grant Award).

\section{Acknowledgements}

We would like to acknowledge East End Foods in their support of this study.

\section{Author details}

${ }^{1}$ Metabolic Medicine, Sandwell General Hospital, Sandwell and West Birmingham Hospitals NHS Trust, Lyndon, West Bromwich, Lyndon (B71 4HJ), UK. ${ }^{2}$ University of Birmingham Centre for Cardiovascular Sciences, City Hospital, Sandwell and West Birmingham Hospitals NHS Trust, Dudley Rd, Birmingham (B18 7QH) UK. ${ }^{3}$ Primary Care Clinical Sciences, University of Birmingham, Vincent Drive, Birmingham, (B15 2TT) UK.

\section{Authors' contributions}

JVP conceived and designed the study, and drafted the manuscript. All authors have participated in the design and co-ordination of this research, the acquisition of funding, and have read and approved the final manuscript.

\section{Competing interests}

The authors declare that they have no competing interests.

Received: 6 October 2011 Accepted: 2 December 2011 Published: 2 December 2011

\section{References}

1. Gill PS, Kai J, Bhopal RS, Wild S: Health Care Needs Assessment: Black and Minority Ethnic Groups. In Health Care Needs Assessment. The epidemiologically based needs assessment reviews. Third Series. Edited by: Raftery J, Stevens A, Mant J. Abingdon: Radcliffe Medical Press Ltd. Oxford;

2. Lip GYH, Barnett A, Bradbury A, Cappuccio F, Gill PS, Hughes E, Imray C, Jolly K, Patel KR: Ethnicity and cardiovascular disease prevention in the United Kingdom: a practical approach to management. J Human Hypertens 2006.
3. Davis TME, Cull CA, Holman RR, for the U.K Prospective Diabetes Study (UKPDS) Group: Relationship between ethnicity and glycaemic control, lipid profiles, and blood pressure during the first 9 years of type 2 diabetes. U.K. Prospective Diabetes Study (UKPDS 55). Diabetes Care 2001, 24:1167-1174.

4. Raleigh VS, Kiri V, Balarajan R: Variations in mortality from diabetes mellitus, hypertension and renal disease in England and Wales by country of birth. Health Trends 1997, 28:122-127.

5. Cruickshank JK, Cooper J, Burnett M, MacDuff J, Drubra U: Ethnic differences in fasting plasma C-peptide and insulin in relation to glucose tolerance and blood pressure. Lancet 1991, 338:842-847.

6. Joshi P, Islam S, Pais P, Reddy S, Dorairaj P, Kazmi K, Pandey MR, Haque S, Mendis S, Rangarajan S, Yusuf S: Risk factors for early myocardial infarction in South Asians compared with individuals in other countries. JAMA 2007, 297:286-94.

7. Olijhoek JK, van der Graaf Y, Banga JD, Algra A, Rabelink TJ, Visseren FL, the SMART Study Group: The metabolic syndrome is associated with advanced vascular damage in patients with coronary heart disease, stroke, peripheral arterial disease or abdominal aortic aneurysm. Eur Heart J 2004, 25:342.

8. Isomaa B, Almgren P, Tuomi T, Forsen B, Lahti K, Nissen M, Taskinen MR, Groop L: Cardiovascular morbidity and mortality associated with the metabolic syndrome. Diabetes Care 2001, 24:683-9.

9. Lakka HM, Laaksonen DE, Lakka TA, Niskanen LK, Kumpusalo E, Tuomilehto J, Salonen JT: The metabolic syndrome and total and cardiovascular disease mortality in middle-aged men. JAMA 2002, 288:2709-16.

10. South Asian Health. [http://www.nhs.uk/Livewell/SouthAsianhealth/Pages/ SouthAsianhealthhub.aspx?WT.mc_id = 21006], (accessed 20/09/2011),

11. Vyas A, Haidery AZ, Wiles PG, Gill S, Roberts C, Cruickshank JK: A pilot randomized trial in primary care to investigate and improve knowledge, awareness and self-management among South Asians with diabetes in Manchester. Diabet Med 2003, 20:1022-6.

12. Gill PS, Lloyd C: Participation in research. In Diabetes UK and South Asian Health Foundation Recommendations on Diabetes Research Priorities for British South Asians.. first edition. Edited by: Khunti K, Kumar S. Diabetes UK, London, UK; 2009:.

13. Patel JV, Vyas A, Cruickshank JK, Prabhakaran D, Hughes E, Reddy KS, Mackness Ml, Bhatnagar D, Durrington PN: Impact of migration on coronary heart disease risk factors: comparison of Gujaratis in Britain and their contemporaries in villages of origin in India. Atherosclerosis 2006, 185:297-306.

14. Patel JV, Vyas A, Prabhakaran D, Bhatnagar D, Durrington PN, Heald A Hughes EA, Mackness MI, Reddy KS, Cruickshank JK: Nonesterified fatty acids as mediators of glucose intolerance in Indian Asian populations. Diabetes Care 2005, 28:1505-7.

15. Kooner JS, Bliga RR, Wilding J, Crook D, Packard CJ, Banks LM, Peart S, Aitman TJ, Scott J: Abdominal obesity, impaired nonesterified fatty acid suppression, and insulin-mediated glucose disposal are early metabolic abnormalities in families with premature myocardial infarction. Arteriosclerosis Thrombosis \& Vascular Biology 1998, 18:1021-1026.

16. Hanley AJG, Williams K, Stern MP, Haffner SM: Homeostasis model assessment of Insulin resistance in relation to the incidence of cardiovascular disease: The San Antonio Heart Study. Diabetes Care 2002, 25:1177-1184.

17. Wolever TM, Jenkins DJ, Vuksan V, Jenkins AL, Wong GS, Josse RG: Beneficial effect of low-glycemic index diet in overweight NIDDM subjects. Diabetes Care 1992, 15:562-4.

18. Wolever TM, Mehling C: Long-term effect of varying the source or amount of dietary carbohydrate on postprandial plasma glucose, insulin, triacylglycerol, and free fatty acid concentrations in subjects with impaired glucose tolerance. Am J Clin Nutr 2003, 77:612-21.

19. Brand-Miller JC, Liu V, Petocz P, Baxter RC: The glycemic index of foods influences postprandial insulin-like growth factor-binding protein responses in lean young subjects. Am J Clin Nutr 2005, 82:350-4.

20. Chadha SL, Gopinath N, Katyal I, Shekhawat S: Dietary profile of adults in an urban \& a rural community. Ind J Med Res 1995, 101:258-67,

21. Urooj A, Puttaraj S: Glycaemic responses to cereal-based Indian food preparations in patients with non-insulin-dependent diabetes mellitus and normal subjects. Brit J Nut 2000, 83:483-8. 
22. Patel JV, Gunarathne A, Lane D, Lim HS, Tracey I, Panja NC, Lip GY, Hughes EA: Widening access to cardiovascular healthcare: community screening among ethnic minorities in inner-city Britain - the Healthy Hearts Project. BMC Health Serv Res 2007, 23;7:192.

23. Heald AH, Golding C, Sharma R, Siddals K, Kirk S, Lawton C, Anderson S, Martin Gibson J, Cade JE: A substitution model of dietary manipulation is an effective means of optimising lipid profile, reducing C-reactive protein and increasing insulin-like growth factor-1. British Journal of Nutrition 2004, 92:809-818.

24. Preece MA, McIntosh WB, Tomlinson S, Ford JA, Dunnigan MG, O'Riordan JL: Vitamin-D deficiency among Asian immigrants to Britain. Lancet 1973, 1(7809):907-10.

25. Solanki T, Hyatt RH, Kemm JR, Hughes EA, Cowan RA: Are elderly Asians in Britain at a high risk of vitamin D deficiency and osteomalacia? Age Ageing 1995, 24:103-7.

26. Awumey EM, Mitra DA, Hollis BW, Kumar R, Bell NH: Vitamin D metabolism is altered in Asian Indians in the southern United States: a clinical research.

27. Durrington PN, Bhatnagar D, Mackness MI, Morgan J, Julier K, Khan MA, France M: An omega-3 polyunsaturated fatty acid concentrate administered for one year decreased triglycerides in simvastatin treated patients with coronary heart disease and persisting hypertriglyceridaemia. Heart 2001, 85:544-8.

28. Patel JV, Tracey I, Hughes EA, Lip GY: Omega-3 polyunsaturated acids and cardiovascular disease: notable ethnic differences or unfulfilled promise? J Thromb Haemost 2010, 8:2095-104.

29. Manav M, Su J, Hughes K, Lee HP, Ong CN: Omega-3 fatty acids and selenium as coronary heart disease risk modifying factors in Asian Indian and Chinese males. Nutrition 2004, 20:967-73.

30. Lovegrove JA, Lovegrove SS, Lesauvage SV, Brady LM, Saini N Minihane AM, Williams CM: Moderate fish-oil supplementation reverses low-platelet, long-chain n-3 polyunsaturated fatty acid status and reduces plasma triacylglycerol concentrations in British Indo-Asians. Am J Clin Nutr 2004, 79:974-82.

31. Sevak L, McKeigue PM, Marmot MG: Relationship of hyperinsulinemia to dietary intake in south Asian and European men. Am J Clin Nutr 1994, 59:1069-74.

32. Gupta N, Shah P, Goel K, Misra A, Rastogi K, Vikram NK, Kumari V, Pandey RM, Kondal D, Wasir JS, Bhardwaj S, Gulati S: Imbalanced dietary profile, anthropometry, and lipids in urban asian Indian adolescents and young adults. J Am Coll Nutr 2010, 29:81-91.

\section{Pre-publication history}

The pre-publication history for this paper can be accessed here: http://www.biomedcentral.com/1471-2261/11/70/prepub

doi:10.1186/1471-2261-11-70

Cite this article as: Patel et al:: Diabetes Health, Residence \& Metabolism in Asians: the DHRMA study, research into foods from the Indian subcontinent - a blinded, randomised, placebo controlled trial. BMC Cardiovascular Disorders 2011 11:70.

\section{Submit your next manuscript to BioMed Central and take full advantage of:}

- Convenient online submission

- Thorough peer review

- No space constraints or color figure charges

- Immediate publication on acceptance

- Inclusion in PubMed, CAS, Scopus and Google Scholar

- Research which is freely available for redistribution

Submit your manuscript at www.biomedcentral.com/submit
Biomed Central 